\title{
Relações de trabalho no serviço de teleatendimento
}

\section{Labor relations in call center service}

\author{
Marlucy Godoy Ricci ${ }^{1}$ \\ Alessandra Rachid ${ }^{2}$
}

\begin{abstract}
Resumo: O objetivo deste trabalho é analisar como a organização do trabalho nas centrais de teleatendimento interfere no processo social de identificação com a profissão e na organização coletiva dos trabalhadores. Para isso, apresentam-se informações sobre o crescimento dos serviços e da atividade de teleatendimento e analisa-se a maneira como o trabalho do operador se encontra organizado dentro das centrais, a partir de um levantamento bibliográfico e de um estudo de caso em uma empresa que realiza cobrança por telefone. Os resultados da pesquisa apontam para a fraca identificação com a profissão, que aparece como um dos motivos para a baixa adesão à organização coletiva.
\end{abstract}

Palavras-chave: Organização do trabalho. Organização coletiva. Teleatendimento. Sindicatos. Serviços.

\begin{abstract}
The purpose of this paper is to analyze how the work organization in call centers interferes in the social process of occupational identification and in the workers' collective organization. To this end, information about the service growth and the activity of telemarketing is provided, and an analysis of how the call center operator's work is organized is presented through a literature review and a case study in a debt collection call center. The results obtained indicate weak occupational identification, which is one of the reasons for low membership rate in the collective organization.
\end{abstract}

Keywords: Work organization. Collective organization. Telemarketing. Labor union. Services.

\section{Introdução}

Os serviços vêm aumentando sua participação relativa na geração de empregos e de riquezas nas últimas décadas. Seu crescimento está atrelado a uma série de fatores, como a externalização de atividades e o desenvolvimento da tecnologia da informação.

O teleatendimento é uma atividade que cresce justamente em função destes aspectos, pois envolve a prestação de serviços para outras empresas e é intensiva em tecnologia da informação.

O serviço de teleatendimento também desperta atenção devido à sua capacidade de gerar empregos e às diferentes formas de controle que atuam sobre o operador. A tecnologia promoveu a automação da prestação desse serviço, imprimindo um ritmo intenso de trabalho, reforçando o controle sobre o trabalhador. $\mathrm{O}$ ambiente de trabalho na área operacional das centrais de teleatendimento é caracterizado pela presença de um roteiro que padroniza a conduta do trabalhador e pela fácil visualização de sua situação de trabalho por parte da supervisão.

A organização do trabalho estimula também a competição entre os trabalhadores, que precisam atingir metas individuais e coletivas, o que leva a mais uma forma de controle, exercido pelos próprios colegas de trabalho. $\mathrm{O}$ trabalho é intenso, o tempo de descanso é pequeno, o que criou um estigma negativo associado à profissão, na qual a taxa de rotatividade é alta. Este contexto acaba dificultando a identificação com a profissão.

Estas características despertam o interesse em analisar a atuação sindical, tema relevante para a organização do trabalho, como destaca Salerno (2004) na análise que faz da área. Sendo assim, este trabalho tem como objetivo explorar as características da organização do trabalho do operador de teleatendimento, a identificação com a profissão e a atuação sindical desta categoria profissional. O artigo discute como a organização do trabalho pode dificultar as estratégias de defesa coletiva.

O trabalho está estruturado da seguinte forma: inicialmente, apresentam-se a evolução e o crescimento do setor de serviços, depois o crescimento das centrais de atendimento, os call centers e, por fim, apresentam-se a análise sobre a organização do trabalho, as fontes de controle que atuam sobre o operador, as características das atividades que levam

\footnotetext{
${ }^{1}$ Departamento de Engenharia de Produção, Centro de Ciências Exatas e de Tecnologia, Universidade Federal de São Carlos - UFSCar, Rod. Washington Luiz, Km 235, Monjolinho, CP 676, CEP 13565-905, São Carlos, SP, Brasil, e-mail: marlucy@ fmr.edu.br

${ }^{2}$ Faculdade Marechal Rondon - FMR, Vicinal Dr. Nilo Lisboa Chavasco, 5000, CEP 18650-000, São Manuel, SP, Brasil, e-mail: arachid@ufscar.br
}

Recebido em 13/12/2010 — Aceito em 5/9/2012

Suporte financeiro: Nenhum. 
à fraca identificação com a profissão e os possíveis reflexos disso na atuação sindical.

\section{Procedimentos de pesquisa}

As informações apresentadas neste texto foram obtidas por meio de um levantamento bibliográfico, em páginas especializadas na internet e de uma pesquisa em uma central de teleatendimento que presta serviços de cobrança por telefone, localizada no interior do Estado de São Paulo.

A pesquisa na empresa envolveu a observação direta e a realização de um total de 53 entrevistas. Com exceção do Diretor de Comunicação e o Presidente, as entrevistas seguiram um roteiro semiestruturado, aplicado ao Gerente de Operações, analistas da qualidade, monitores, assistentes e operadores. Todos os entrevistados por meio do questionário ingressaram na empresa como operadores e, portanto, também forneceram informações sobre o trabalho de operador.

$\mathrm{O}$ roteiro teve que ser aprovado pela direção da empresa, que pediu para que fossem retiradas as questões relacionadas à satisfação com o trabalho, à autonomia de decisão e à filiação ao sindicato. Por isso, as informações sobre a atuação do sindicato restringiram-se àquelas obtidas no sindicato, por meio de entrevistas e consultas a documentos.

\section{$3 \mathrm{O}$ crescimento do setor de serviços}

O desenvolvimento exponencial dos serviços dentro das economias desenvolvidas está relacionado ao contexto de mundialização ocorrida a partir do final dos anos 1990. De acordo com Kon (2006), a acumulação de capital foi intensificada por meio da capacidade da economia funcionar em tempo real, como uma unidade, em escala mundial. Tal processo, associado ao desenvolvimento da tecnologia da informação e comunicação, tem conduzido à inovação organizacional, a novas formas de comercialização e ao surgimento de novas modalidades de serviços, despertando o interesse sobre esta nova dinâmica.

$\mathrm{O}$ advento da microeletrônica tornou alguns serviços intensivos em tecnologia, desmentindo a afirmação de que inovações tecnológicas não poderiam ser realizadas dentro deste setor. Segundo Kubota (2006), estas tecnologias tornaram as informações mais fáceis de serem separadas, comercializadas e transferidas, o que viabilizou o comércio internacional de alguns serviços, atribuindo ao setor uma importante participação na balança de pagamentos de alguns países.

Além disso, tornou-se possível a produção de serviços de forma mais padronizada, mais integrada entre diferentes unidades e com alta divisão do trabalho, como nas redes de fast food e nas centrais de teleatendimento. Nestas, observa-se ainda que parte da atividade humana foi automatizada.

Os dados apresentados na Tabela 1 apontam o aumento da importância do setor de serviços na geração de novas empresas. Observa-se que o número de empresa de serviços cresceu mais do que o do comércio e da indústria de transformação. No ano de 2006, o número de empresas que prestavam serviços a outras empresas foi de 223.819, de acordo com os dados do IBGE. No entanto, a receita líquida gerada nos serviços tem um desempenho pior, representando aproximadamente um terço do valor movimentado na indústria e metade do movimentado no comércio, como mostrado na Tabela 1.

Tabela 1. Números de empresas e receita líquida na indústria, comércio e serviços (1991 e 2003).

\begin{tabular}{cccc}
\hline Setor & $\mathbf{1 9 9 1}$ & $\mathbf{2 0 0 3}$ & Crescimento (\%) \\
\hline \multicolumn{4}{c}{ Número empresas } \\
\hline Indústria & 117.838 & 138.962 & 18 \\
Comércio & 1.038 .509 & 1.365 .136 & 31 \\
Serviços & 650.479 & 922.748 & 42 \\
\hline Indústria & \multicolumn{1}{c}{ Receita líquida (R\$ 1000) } & 45 \\
Comércio & 675.737 .350 & 982.344 .538 & 23 \\
Serviços & 551.292 .767 & 675.587 .092 & 30 \\
\hline
\end{tabular}

Fonte: Silva, De Negri e Kubota (2006), a partir de dados do IBGE.

Tabela 2. PIB por setor da economia - Brasil (milhões de reais).

\begin{tabular}{lcrrrrr}
\hline \multicolumn{1}{c}{ Setor } & $\mathbf{2 0 0 0}$ & $\boldsymbol{\%}$ & $\mathbf{2 0 0 7}$ & $\mathbf{\%}$ & \multicolumn{1}{c}{$\mathbf{2 0 0 8}$} & \multicolumn{1}{c}{} \\
\hline Agropecuário & 57.241 & 5,6 & 133.016 & 6,0 & 163.535 & 6,7 \\
Industrial & 283.320 & 27,7 & 623.721 & 28,1 & 682.496 & 28,0 \\
Serviços & 681.086 & 66,7 & 1.466 .784 & 66,0 & 1.595 .022 & 65,3 \\
Total & 1.021 .647 & 100,0 & 2.223 .521 & 100,0 & 2.441 .053 & 100,0 \\
\hline
\end{tabular}

Fonte: elaborado a partir de IBGE (INSTITUTO..., 2007b, 2009). 
Comércio e serviços, juntos, têm respondido por cerca de 66\% do PIB (Produto Interno Bruto), como mostra a Tabela 2.

Também tem crescido muito a importância do setor na geração de empregos. Os dados da Tabela 3 mostram que, entre 1994 e 2000, houve um crescimento de $141,3 \%$ dos empregos em serviços, ao mesmo tempo que houve uma retração na indústria de transformação. Em 2007, segundo o DIEESE (DEPARTAMENTO..., 2009), 31,7\% dos empregos formais concentravam-se no setor de serviços.

Não há uma explicação única para a expansão do setor, sendo mais apropriado falar na convergência de fatores, cujos desdobramentos ainda não são suficientemente claros. Uma das explicações vem do papel de facilitador das transações econômicas que os serviços assumem, essenciais à indústria de transformação. Para Kon (2006), esta interação entre serviços e produção manufatureira tornou-se uma força impulsionadora do desenvolvimento econômico.

A interdependência entre estes dois setores revela outro papel dos serviços, o de "colchão amortecedor" do desemprego, ou seja, na insuficiência de oferta de emprego, parte do contingente de desempregados acaba sendo absorvida em atividade de serviços, não raro em empregos mal remunerados, quando não informais (SILVA, 2005).

De acordo com Oliveira (2001), desde o avanço da industrialização por substituição de importações, nos anos 40, se verifica o acréscimo da força de trabalho nas atividades alocadas no setor terciário. Para Braga (2006), o emprego, principalmente nos países industrializados, "deslizou" em direção aos serviços. Esse deslizamento foi particularmente intenso nos anos 1990, devido à intensidade da terceirização, uma vez que muitas das atividades externalizadas passam do setor secundário para o terciário.
Apesar dos serviços crescerem em termos de oferta de emprego, verifica-se o mesmo processo de racionalização e flexibilização do trabalho que caracteriza a reestruturação produtiva vivenciada pelo setor industrial nos anos 1980 (SEGNINI, 1999). A racionalização e a tecnologia viabilizaram maior controle e rigidez do comportamento do trabalhador, permitindo o aumento da produtividade das atividades de serviços.

Segundo Segnini (1999), serviços de bancos, hospitais, correios e telefonia são exemplos de serviços que vivenciam a intensificação deste processo de racionalização do trabalho.

O teleatendimento é um dos serviços que passou por um grande crescimento nos últimos anos, o que é explorado no item seguinte.

\section{As centrais de teleatendimento}

Os termos telemarketing, call center, central de atendimento ou teleatendimento são utilizados na literatura e na mídia sem diferenciação.

Independente do nome que seja dado, [...] consistem em um local onde se concentra o relacionamento com os clientes, seja ele realizado através de telefone, e-mail, web site, fax ou outra tecnologia [...] (JAMIL; SILVA, 2005, p. 100).

No ano de 2002, uma pesquisa da ABT estimava que o volume de transações apoiadas por este tipo de serviço teria ultrapassado os $\mathrm{R} \$ 67$ bilhões obtidos no ano anterior, o que representaria mais de $6 \%$ do PIB brasileiro. Entre os anos de 2000 e 2004, o faturamento bruto deste mercado, no Brasil, ainda de acordo com esta Associação, cresceu de US\$ 520 milhões para US\$ 3 bilhões (OLIVEIRA et al., 2005).

$\mathrm{O}$ site CallCenter.Inf apresenta outros dados, levantados a partir das informações divulgadas pelas

Tabela 3. Emprego nos setores secundário e terciário (Brasil, 1994 a 2004, milhões).

\begin{tabular}{lccccc}
\multicolumn{1}{c}{ Setor/Ano } & $\mathbf{1 9 9 4}$ & $\mathbf{2 0 0 0}$ & Variação (\%) & $\mathbf{2 0 0 4}$ & Variação (\%) \\
\hline Indústria de transformação & 7,0 & 6,7 & $-3,0$ & 8,6 & 26,7 \\
Serviços & 9,1 & 22,0 & 141,3 & 28,4 & 29,2 \\
\hline
\end{tabular}

Fonte: IBGE (INSTITUTO..., 1997, 2002, 2007a).

Tabela 4. Faturamento das Centrais de Teleatendimento Brasileiras.

\begin{tabular}{cccccc}
\hline Ano & $\begin{array}{c}\text { Faturamento } \\
\text { (R\$ milhões) }\end{array}$ & $\begin{array}{c}\text { Postos de } \\
\text { Atendimento (PAs) }\end{array}$ & $\begin{array}{c}\text { Faturamento } \\
\text { médio/PAs (R mil) }\end{array}$ & $\begin{array}{c}\text { Número de } \\
\text { funcionários }\end{array}$ & $\begin{array}{c}\text { Faturamento médio/ } \\
\text { func. }(\mathbf{R} \text { mil) }\end{array}$ \\
\hline 2004 & $2.962,8$ & 70.321 & 42,1 & 140.156 & 21,1 \\
2005 & $4.162,9$ & 86.810 & 48 & 194.543 & 21,4 \\
2006 & $5.305,5$ & 100.390 & 50,2 & 224.804 & 22,4 \\
2007 & $4.786,3$ & 104.620 & 45,7 & 221.044 & 21,7 \\
2008 & $6.350,4$ & 120.527 & 52,7 & 254.633 & 24,9 \\
2009 & $7.098,1$ & 127.809 & 55,5 & 266.738 & 26,6 \\
\hline
\end{tabular}

Fonte: CallCenter.Inf. (2010). 
próprias empresas, refletindo, portanto, somente as empresas que publicaram seus resultados. Esses dados estão na Tabela 4, que apresenta a evolução do faturamento das centrais brasileiras entre 2004 e 2009.

De acordo com o site Convergência Digital (2009), por sua vez, o setor encerrou 2008 com um faturamento de $\mathrm{R} \$ 5,5$ bilhões e 850 mil empregos.

De acordo com Borges e Rosa (2007), o crescimento dessa atividade entre 2005 e 2009 foi da ordem de $25 \%$, e a previsão para 2010 estava em torno de $8 \%$ a 10\%. Já Antonelli (2008) apresenta dados de um estudo realizado pelo International Data Corporation que prevê um faturamento em torno de US\$ 200 milhões, o que corresponde a uma média de crescimento anual em torno de $12 \%$ até 2012.

Apesar das discrepâncias, os dados apresentados são ilustrativos de uma tendência de crescimento que vem sendo tratada por estudos acadêmicos da área (BAGNARA; MARTI, 2001; GEORGES, 2006; VENCO, 2006) e, frequentemente, aparecem nos meios de comunicação em massa.

Esse ritmo de crescimento tornou o teleatendimento um grande gerador de empregos. A Tabela 5 apresenta a evolução ascendente no número de postos de atendimento e no número de operadores entre os anos de 2004 e 2009, de acordo com dados do site CallCenter.Inf.

Para Braga (2006), o setor de teleatendimento é composto por atividades de baixo valor agregado e que atraem uma força de trabalho pouco qualificada e formada basicamente por jovens e estudantes. Este é alvo de críticas devido à padronização da conduta do teleatendente e devido às diferentes fontes de controle que atuam sobre ele, dificultando a identificação com a profissão e a criação de laços de amizade entre os trabalhadores.

O controle exercido sobre o teleatendente constitui questão interessante dado que o trabalho é pautado na prestação de serviço de teleatendimento, o que, por natureza, demanda flexibilidade e autonomia. No entanto, existe um forte controle e padronização.

\section{O trabalho do teleatendente e as fontes de controle}

O trabalho do operador de teleatendimento está apoiado em modernas tecnologias, porém, em sua essência, ele se mantém centrado em atender e efetuar chamadas telefônicas. A tecnologia não alterou a natureza da atividade em si, mas intensificou o volume de produção. As técnicas e métodos aplicados na organização do trabalho se assemelham àquelas antes observadas na indústria de transformação.

A intensificação do ritmo de trabalho pelo aumento do número de ligações é resultado, segundo Durand (2004), da eliminação dos tempos mortos entre as tarefas, suprimindo o período de recuperação dos trabalhadores. Isso pode ser verificado na pausa entre uma chamada e outra, denominada temporização. Segundo Venco (2006), na França, a temporização oscila entre sete e vinte segundos, permitindo descansos de apenas 5 a 12 minutos por hora, determinados pelo teleatendente, em consonância com seu chefe de equipe e conforme o número de clientes em espera.

O site Guia Call Center Brasil realizou uma enquête, sob demanda da autora do presente texto, para esta pesquisa, para verificar a temporização nas centrais no país. A enquete ficou aberta no site entre os dias 20 e 31 de janeiro de 2010 e foi respondida por mais de 34 mil pessoas que atuam nessa atividade. Seus resultados são apresentados na Tabela 6.

A relação entre tecnologia e intensificação do trabalho e do controle sobre este é um fenômeno bem explorado pela literatura (BURAWOY, 1983; CASTRO; GUIMARÃES, 1991; GITAHY, 1994; SALERNO, 2004). Edwards (1979) observou, no setor industrial, que "[...] a tecnologia informática dá um impulso formidável aos métodos primitivos de controle técnico [...]" (p. 112). Braverman (1974) argumenta que a introdução de novas tecnologias faz prevalecer, no setor de serviços, as mesmas normas de rotinização, fragmentação e desqualificação do trabalho vigente na indústria.

Nas centrais de teleatendimento, essa racionalização é verificada e contribui para a constituição de um espaço marcado por contradições, uma vez que

Tabela 5. Postos de atendimento e operadores nas centrais de teleatendimento (2004 a 2009).

\begin{tabular}{ccc}
\hline Ano & $\begin{array}{c}\text { Posições de } \\
\text { atendimento }\end{array}$ & $\begin{array}{c}\text { Total de } \\
\text { operadores }\end{array}$ \\
\hline 2004 & 92.445 & 181.960 \\
2005 & 107.845 & 239.111 \\
2006 & 124.706 & 271.142 \\
2007 & 151.563 & 320.425 \\
2008 & 166.826 & 337.867 \\
2009 & 171.842 & 348.036 \\
\hline
\end{tabular}

Fonte: CallCenter.Inf. (2010).

Tabela 6. Temporização em centrais no Brasil.

\begin{tabular}{lcr}
\hline $\begin{array}{c}\text { Pausa entre uma } \\
\text { ligação e outra }\end{array}$ & $\begin{array}{c}\text { Total de } \\
\text { respondentes }\end{array}$ & $\%$ \\
\hline Sem pausa & 9,747 & 28,5 \\
1 a 10 segundos & 10,810 & 31,6 \\
11 a 15 segundos & 4,076 & 11,9 \\
16 a 20 segundos & 2,127 & 6,2 \\
Superior a 20 segundos & 7,442 & 21,8 \\
Total & 34,202 & 100,0 \\
\hline
\end{tabular}

Fonte: enquete do site Guia Call Center Brasil (2010). 
[...] o trabalho em call centers busca associar as competências relacionais e comunicacionais à subordinação a regras e normas inflexíveis de como atingir metas e objetivos definidos de maneira heterônoma [...] (ROSENFIELD, 2007, p. 451).

A autonomia do teleatendente, portanto, é limitada. O trabalho, de acordo com Oliveira (2004), é marcado por um forte controle de conduta, determinando o ritmo, as cadências e os procedimentos, o que revela a presença dos princípios da administração científica na organização do trabalho.

Para Rosenfield (2007), o legado taylorista é identificável porque:

Os tempos são cronometrados nos segundos, inclusive as pausas e a produtividade, com mais precisão do que era possível no trabalho taylorista; há um forte controle dos movimentos e dos gestos, uma vez que o atendente fica preso ao head fone e seu escopo de movimentação restringe-se ao alcance do fio; o próprio processo de trabalho é constantemente monitorado e controlado por meio da gravação das ligações, da supervisão em tempo real, das auditorias, além do controle do volume de vendas em tempo real, de maneira a induzir a vender mais para atingir as metas; há uma importante rotatividade de operadores; a organização do trabalho em postos individualizados de atendimento impõe a individualização do trabalho, de maneira que os operadores devem se remeter sempre à supervisão e nunca aos pares [...] (ROSENFIELD, 2007, p. 452-453).

Autores como Batt e Doellgast (2005), Braga (2006), Delbridge (1998), Oliveira (2004), Rosenfield (2007) e Venco $(1999,2009)$ fazem observações no mesmo sentido e concluem que a função de teleatendente testemunha como nenhum outro a taylorização do trabalho intelectual.

Além do controle pela organização, observa-se também a existência de esquemas de controle que emanam dos próprios trabalhadores. Este ocorre com frequência em empresas em que há grupos de trabalho cujo desempenho é avaliado coletivamente. O desempenho do grupo depende do envolvimento de cada indivíduo e, por isso, os trabalhadores fiscalizam uns aos outros. Na empresa pesquisada, os operadores são divididos em equipes de trabalho, chamadas de "carteiras", cada uma dedicada a um cliente e a um tipo de dívida, que engloba desde financiamento de veículos atrasados a débitos de fatura de cartão de crédito. Cada tipo de dívida tem um procedimento de cobrança diferente.

A concepção de equipe é usada pela empresa para estimular os operadores a atingirem a meta de retorno financeiro definida por cada banco cliente. A central recompensa o operador que cumpre a meta e também os demais membros que compõem a carteira. Esta é uma forma de promover um controle descentralizado, menos visível, como apontado por Smith (1997). Desta forma, cada um passa a fiscalizar o trabalho do outro. Sewell (1998) argumenta que os grupos de trabalho ajudam a complementar as formas de controle hierárquicas, uma vez que estabelecem suas próprias sanções e recompensas.

Segundo Salerno (1999), os esquemas de avaliação de desempenho de grupos, se não forem feitos de uma forma compatível, podem sinalizar no sentido contrário ao da solidariedade entre os membros de um grupo e entre grupos. Para Zarifian (2001), o sucesso das equipes de trabalho depende da ação individual de cada um, o que sempre abre a possibilidade da constituição de uma rede de pressão e controle sobre os membros das equipes de trabalho. Na empresa pesquisada, a recompensa por metas atingidas é dividida de maneira igual entre os membros da carteira. Isso dá margem a conflitos, conforme ilustra as falas a seguir:

Se você não bateu a sua meta individual diária, você prejudica sua equipe toda. Se você não tiver indo de acordo com o que a equipe está trabalhando e se for uma diferença muito grande, você vai se queimar com a sua equipe (Entrevista 22, monitor).

\section{É difícil saber que só um na equipe faz o trabalho e o restante fica ali sem fazer esforços (Entrevista 21, monitor).}

A competição é intensificada pelo fato dos operadores nem sempre chegarem a um acordo com o devedor no primeiro contato. Um mesmo devedor pode receber uma segunda ligação de outro operador. Se este encerrar a negociação, o valor será contabilizado para sua meta. A fala a seguir deixa claro o incômodo que isso causa:

\begin{abstract}
Eu entrei no contrato do devedor X. Outro operador vê que eu já acessei esse contrato, que ele não acessa de novo porque esse contrato já está em acordo e ele precisa respeitar, teoricamente. Só que, geralmente, ocorre briguinha porque um roubou o cliente do outro. [...] Aquele que gera o boleto contabiliza em sua meta diária (Entrevista 22, monitor).
\end{abstract}

Raramente o devedor que retorna a ligação fala com o mesmo operador:

Exemplo: eu liguei para o devedor de manhã, mas se a tarde o devedor retornou e o operador da tarde fechou o acordo, o boleto será dele (Entrevista 22, monitor). 
A impessoalidade do contato com os devedores acirra a competição entre os operadores, pois a meta pertence àquele que fechou o acordo e não àquele que conduziu todo processo de cobrança, levando para a formação de um ambiente de trabalho de pressão e de insatisfação:

[...] é aquela rixa, aquela briga e eu acho que ali, na operação, o que mais a gente vê são as pessoas tristes por causa desse clima de competição (Entrevista 22, monitor).

De acordo com entrevistados, esta competição se reforça entre os trabalhadores do turno da manhã, das $8 \mathrm{~h}$ às $14 \mathrm{~h}, \mathrm{e}$ os da tarde, das $14 \mathrm{~h}$ às $20 \mathrm{~h}$ :

\section{[...] você não consegue fechar muitos acordos no período da tarde [...] pelo fato de trabalharem com pouco espaço do período bancário. Eles entram às duas e o banco fecha às quatro. $O$ pessoal da manhã não tem esse problema, pois pega o banco quase o dia todo (Entrevista 24 , monitor).}

O turno da tarde sempre acha que o turno da manhã tem... Como fala? Privilégio (Entrevista 40, analista de qualidade).

O controle é ainda reforçado pela forma como a área operacional das centrais de teleatendimento são construídas, pois, como ressaltado por Foucault (1987), o espaço físico constitui um elemento de controle quando permite a visibilidade das pessoas dentro dele. $\mathrm{O}$ autor analisa a construção do espaço físico de prisões, hospitais, fábricas, escolas e quartéis militares, e observa como este é coadjuvante do processo disciplinador.

Como Barnes (2007) observou em três centrais na Austrália, as áreas operacionais das centrais de teleatendimento não possuem salas individualizadas, o que ele chama de "open-play layout" (p. 253). Todas possuem grandes salas, sem paredes e os postos de teleatendimento são arranjados em várias posições para dividir os teleoperadores em times, grupos de trabalho e maximizar o uso do espaço físico. Essas áreas constituem espaços nos quais se desenha a rede de olhares que controlam uns aos outros.

Desta forma, “[...] o poder está em toda parte; não porque englobe tudo e sim porque provém de todos os lugares [...]" (FOUCAULT, 2001, p. 89). O controle visual é exercido de maneira permanente e, por isso, se mostra eficiente quando o objetivo é garantir a disciplina dos trabalhadores. É o “[...] olhar hierárquico, a sanção normalizadora e sua combinação num procedimento que lhe é específico: o exame [...]" (FOUCAULT, 1987, p.143).

O poder disciplinador ou biopoder, como foi chamado por Foucault (2001), produz o comportamento social desejado nos indivíduos para o funcionamento e manutenção da sociedade industrial. A vigilância contínua age sobre os indivíduos, controlando o tempo e maximizando a produção. Para o autor, esta arquitetura física procura garantir a qualidade do tempo empregado, com

[...] controle ininterrupto, pressão dos fiscais, anulação de tudo que possa perturbar e distrair; trata-se de constituir um tempo integralmente útil [...] (FOUCAULT, 1987, p.128).

Nas áreas operacionais, cada teleatendente é posicionado em um pequeno compartimento, chamado de baia, com espaço apenas para si e para o computador. Os teleatendentes são separados uns dos outros por meio de divisórias. Esta separação não os isola completamente, mas dificulta, por exemplo, o contato visual. As baias, geralmente, ficam enfileiradas no centro da grande área operacional. Os gerentes e monitores possuem suas mesas de trabalho nesta mesma área e, ao contrário das baias, não possuem nenhuma separação física, o que facilita a supervisão da rotina de trabalho na operação. Para Silveira (2006):

[...] os postos de atendimento são construídos de forma a manter os operadores protegidos de interferências externas, como barulhos e conversas paralelas [...] (2006, p. 48),

mas, ao mesmo tempo, de forma que possam ser monitorados pelos superiores hierárquicos.

Além disso, Burawoy (1983) acredita que os trabalhadores consentem com as regras que lhes são impostas. Para o autor,

[...] o medo de perder créditos de significância social é que impede o indivíduo de escolher condutas alternativas ou contestatórias, mesmo quando delas têm consciência [...] (p. 325).

As regras que dominam os trabalhadores não atuam apenas na esfera econômica, de produção e administração de mercadorias, mas, também, na esfera política e ideológica e de reprodução das relações sociais. A sujeição e a coerção são aceitas coletivamente, pois são compreendidas como constituintes do próprio processo de trabalho e como inevitáveis para se manter empregado e com possibilidade de receber premiações, como ser escolhido o funcionário do mês por ter atingido as metas de retorno financeiro, como no caso da empresa estudada.

Para Castro e Guimarães (1991), é o significado cultural e simbólico partilhado por gerentes e trabalhadores que garantem o êxito mobilizador, entendido aqui como fator disciplinador e motivador de sujeição à dominação. Isso acaba se refletindo e, ao mesmo tempo, sendo reforçado, pela baixa taxa de sindicalização, tema do próximo item. 


\section{A profissão e a organização coletiva}

O clima de competição entre os operadores de teleatendimento, apontado no item anterior, é um dos fatores que dificultam a organização coletiva desta categoria. Para Heloani e Capitão (2003), este tipo de situação, de vigilância mútua entre os trabalhadores, distorce qualquer senso de confiança e comprometimento mútuo, inviabiliza a cooperação e impede a criação de identificação entre os pares. Para Rosenfield (2007), a impossibilidade de se criar uma identidade individual e social, desvincula o trabalho da realização pessoal.

Para Braga (2006), a construção da identificação no ambiente de trabalho depende do equilíbrio na relação entre reconhecimento, autonomia e cooperação. Estes fatores são chave, mas sua relação é deficitária dentro do ambiente das centrais, nas quais a limitação da autonomia associada a um ambiente de controle e de competição constitui um cenário que inviabiliza a sensação de ser reconhecido e de querer ser parte do meio, dificultando ainda mais a coesão dessa categoria profissional.

Além disso, há uma visão de que este é um emprego passageiro. Segundo Oliveira et al. (2005), a taxa de rotatividade média é de $38,6 \%$, sendo que o tempo médio de permanência dos operadores nas empresas de teleatendimento é de 2,4 anos. Como disse um dos entrevistados, "a função de operador tem um prazo de validade". Na visão dele, isso ocorre em função dos prejuízos causados à saúde, mas isso também se deve às limitadas possibilidades de evolução na carreira, como apontado por Mocelin e Silva (2008) e Rosenfield (2007).

Segundo Georges (2005), “[...] o trabalho no setor de telemarketing não constitui uma perspectiva profissional em si mesma [...]" (p. 11). Segundo Aragão (2008), isso ocorre porque os operadores não desejam permanecer trabalhando nesta atividade. A visão negativa da profissão faz com que a identificação com a categoria não seja expressiva (MOCELIN; SILVA, 2008).

No caso da empresa pesquisada, a falta de identificação acaba sendo reforçada por se tratar de uma empresa de cobrança por telefone, já que a função de cobrador é estigmatizada. Na tentativa de fugir deste estigma negativo, a central de cobrança estudada se refere aos operadores como sendo "recuperadores de crédito". Esse esforço por parte da empresa é prontamente aceito pelos trabalhadores.

A falta de identificação com a profissão pode ser visto como um dos fatores que ajudam a explicar a baixa adesão dos operadores aos sindicatos. Em uma pesquisa de comparação internacional envolvendo 17 países, incluindo o Brasil, e 2500 centrais de atendimento, menos da metade das centrais tinham alguma forma de representação coletiva e apenas 35\% contavam com acordos coletivos (BATT; HOLMAN; HOLTGREWE, 2009).

Na pesquisa realizada por Oliveira et al. (2005) no Brasil, 50,4\% dos 114 questionários respondidos pelas 103 organizações participantes responderam "zero" à pergunta sobre o percentual de empregados que fazem parte de um sindicato. Quando se comparam as respostas das centrais próprias com as das centrais terceirizadas, os valores são de " $62,9 \%$ e $42,1 \%$, respectivamente, diferença de 20 pontos percentuais" (p. 47).

Diversos autores têm analisado a perda do dinamismo da organização coletiva dos trabalhadores (BEAUD; PIALOUX, 1999; BRAGA, 2006; CARDOSO, 2008; NORONHA, 2009). Outro aspecto observado por Araújo et al. (2006), em pesquisa na indústria de eletrodomésticos, foi uma menor taxa de filiação ao Sindicato dos Metalúrgicos entre os trabalhadores mais novos. De acordo com Beaud e Pialoux (1999), a fragmentação do grupo operário é um dos fenômenos que contribui para a individualização dentro do ambiente de trabalho, o que ajuda a impactar a sua articulação política, enfraquecendo as estratégias de resistência.

Segundo Braga (2006), o contexto de criação e crescimento das centrais de teleatendimento coincide com esse período de desmobilização. Isso se reforça diante de características próprias desta atividade, como o fluxo intenso de trabalho, pouca autonomia de decisão, competição entre trabalhadores por produtividade e pelas distintas fontes de controle observadas.

Ainda segundo Braga (2006), a maneira como a área operacional das centrais de teleatendimento está construída também contribui para a fragmentação do coletivo de trabalhadores, pois dificulta o contato pessoal e enfraquece a criação de sistemas de solidariedade e de defesa coletiva, tornando o grupo ainda mais desprovido de representação e força.

Para Rosenfield (2007),

Se a realidade do trabalho é partilhada pelos pares, ela pode conduzir a uma experiência coletiva. Esta constitui a base sobre a qual pode-se elaborar um sentido comum, uma compreensão comum da realidade. O reconhecimento pelos pares é o reconhecimento realizado pelo outro, que enfrenta as mesmas dificuldades do mundo real e do mundo do trabalho e só ele é capaz de liberar o trabalhador de sua solitude e de desenvolver mecanismos de proteção à dominação através de estratégias de defesa coletiva [...] (p. 780).

A individualização dos comportamentos, para Venco (2006), neutraliza a mobilização coletiva e generaliza o silêncio e o "cada um por si", o que inviabiliza a criação de uma identificação do grupo e, por consequência, inibe a sua representatividade, 
transformando os teleoperadores em uma categoria profissional desprovida de força e mais suscetível às condições negativas de seu trabalho. Observa-se, de acordo com Rosenfield (2007), o fortalecimento da relação com a empresa, o que reforça as estratégias individuais e enfraquece a relação com os pares.

A fragmentação do coletivo é mais intensa dentro das centrais terceirizadas. Ao dividir o conjunto de trabalhadores em diferentes empresas e categorias, a terceirização dificulta a atuação dos sindicatos, que têm procurado resistir a seu avanço, ainda que de forma defensiva (DRUCK; FRANCO, 2008; FIGUEIREDO et al., 2007; SANCHES, 2006).

Segundo Mocelin e Silva (2008), com a terceirização, o elo trabalhador-empresa se torna menos visível, uma vez que os empregados confundem quem é o seu real empregador, o que contribui para acentuar a sensação de individualização no ambiente de trabalho. Essa falta de visibilidade, para os autores, é um fenômeno social denominado desterritorialização.

A desterritorialização consiste na dificuldade que os empregados de uma empresa terceirizada experimentam, uma vez que são contratados por uma empresa, mas trabalham para outra. Seria difícil para o empregado criar uma identidade com a operadora, uma vez que oscilam entre o empregador - que é a operadora - e o cliente da operadora - para quem o empregado presta o serviço de telemarketing (MOCELIN; SILVA, 2008, p. 375-376).

Este fenômeno se reforça em casos de terceirização do teleatendimento para o mercado internacional. Os principais países exportadores de serviço de teleatendimento são a Índia, a Filipinas e o México, mas o Brasil também tem exportado esse serviço (CALLCENTER.INF, 2009b). De acordo com a Associação Brasileira de Telesserviço (ASSOCIAÇÃO..., 2006), 20\% das posições de atendimento eram voltadas para o exterior, com 500 a 700 operadores bilíngues.

Rosenfield (2007) e Venco (2006) apresentam ainda, como motivo para a baixa adesão aos sindicatos, o fato do setor ser relativamente novo. No Brasil, este ganhou expressão a partir da década de 1990. De acordo com Laranjeira (2003), a desregulamentação e privatização das telecomunicações no Brasil levaram a uma diversificação de atividades, que compreendem telefonia fixa e móvel, processamento de dados, serviços de TV por assinatura, de publicação, internet e de informação. Essa ampliação, de acordo com a autora, tem alterado a categoria, que passa do setor de telecomunicações para o setor da informação e, na medida em que se transforma na chamada indústria da informação, a influência dos sindicatos se reduz. Além disso, o teleatendimento é caracterizado pela heterogeneidade em relação aos serviços prestados, que variam desde serviços de vendas a serviços de help desk.

A diversificação das atividades dificulta a organização e a intervenção sindical e, segundo Georges (2006), essa relação é recíproca porque a "dificuldade de intervenção sindical contribui para essa heterogeneidade" (p. 16), pois cria dúvidas na escolha do sindicato a se filiar. Geralmente, o sindicato que tem mais apelo em termos de assistência e benefícios atrai mais filiados. Porém, isso dependerá diretamente do poder político de influência do sindicato na região em que atua (LARANJEIRA, 2003).

Além de se expandirem em áreas que não possuem uma história de sindicalização, como no caso dos serviços de computação e informação, essa diversificação das atividades dificulta o reconhecimento da categoria sindical que os representa. Para Laranjeira (2003), os trabalhadores de teleatendimento podem se filiar tanto aos sindicatos que abrangem as áreas de telecomunicações, quanto em

[...] outras categorias sindicais como, por exemplo, o sindicato do comércio, cuja lógica e funcionamento são muito diferentes da dos sindicatos de telecomunicações [...] (p. 94).

Isso tem levado a uma disputa pela representação dos operadores de teleatendimento. Segundo Corrochano e Nascimento (2007), na região metropolitana de São Paulo, por exemplo, a disputa se dá entre o Sindicato dos Trabalhadores em Empresas de Telecomunicações (SINTETEL) e o Sindicato dos Trabalhadores em Telemarketing (SINTRATEL), com 25 e 40 mil filiados, respectivamente (CORROCHANO; NASCIMENTO, 2007).

Na região da empresa pesquisada, a disputa ocorre entre o SINTETEL e o SEAAC (Sindicato dos Empregados de Agentes Autônomos do Comércio e em Empresas de Assessoramento, Perícias, Informações e Pesquisas e de Empresas de Serviços Contábeis), que representam os trabalhadores de quatro empresas de cobrança, incluindo a central pesquisada. O SEEAC tem representação nas seguintes cidades do Estado de São Paulo:

- Americana, com subsedes em Piracicaba e Limeira

- Araraquara, com subsede em São Carlos

- Araçatuba

- Bauru

- Campinas

- Franca

- Jundiaí

- Marília

- Presidente Prudente

- Ribeirão Preto

- Grande ABC, com subsede em Mogi das Cruzes

- Santos 
- São José dos Campos

- São José do Rio Preto

- São Paulo

- Sorocaba (FEDERAÇÃO..., 2010b)

Os SEEACs representam trabalhadores das atividades listadas a seguir:

- Administradores de Consórcio

- Advocacia

- Arquitetura e Engenharia Consultiva

- Arrendamento Mercantil (Leasing)

- Assessoramento, detalhado a seguir

- Cobrança e Recuperação de Crédito

- Comissárias de Despachos, incluindo serviços de transporte de cargas ligadas ao comércio exterior

- Comissários e Consignatários, incluindo locadoras de bens móveis, casas lotéricas, lan houses e cyber cafés

- Contabilidade

- Corretores de Imóveis

- Locadoras de Filmes

- Locadoras de Máquinas e Equipamentos de Terraplenagem

- Representantes Comerciais

- Sociedades de Fomento Mercantil (Factoring) (FEDERAÇÃO..., 2010a)

Em algumas cidades, como Araraquara e Santos, por exemplo, as centrais de cobrança pertencem à categoria "Cobrança e Recuperação de Crédito". Em outras, como Campinas, São Paulo e Ribeirão Preto, as centrais de cobrança pertençam à categoria "Assessoramento", que inclui atividades como:

- Administradoras de Cartões de Crédito

- Auditoria e Consultoria

- Auto Tour Assistência Automobilística

- Cobrança

- Financiadoras

- Fotocópia

- Leilão e Leiloeiros

- Logística

- Manutenção de Computadores

- Manutenção de Plataformas Marítimas

- Mapeamento

- Partidos Políticos

- Pesquisa de Opinião

- Promoção de Eventos

- Promotoras de Vendas

- Remessa de Documentos

- Tradutor

- Outras (SINDICATO..., 2010)

Como pode ser observado, há uma grande diversidade de atividades, o que ilustra bem a dificuldade apontada por Laranjeira (2003), de representar interesses de trabalhadores em serviços muito distintos entre si.

As dificuldades para construção de defesas coletivas, no entanto, não impedem os operadores de desenvolverem estratégias de resistência para minimizarem o controle sobre seu trabalho, porém isso só acaba ocorrendo, muitas vezes, apenas de maneira individual, observado em situações apontadas pelos entrevistados, como apertar a tecla mute, do sistema operacional, para evitar o desgaste de ouvir reclamações dos devedores, ou outras estratégias claramente usadas para criar folgas no ritmo ao longo da jornada.

\section{Conclusões}

A participação do setor de serviços na geração de empregos e de riquezas vem crescendo. Um dos motivos apontados para a sua expansão é sua interdependência com o setor industrial, particularmente na década de 1990, fruto da prática de externalização das atividades industriais. Ao mesmo tempo, observa-se que os serviços também vem passando pelo processo de internacionalização e de racionalização e flexibilização do trabalho, o mesmo vivenciado pelo setor industrial na década anterior.

As empresas de teleatendimento constituem um bom exemplo deste contexto, pois são geradoras de empregos, prestam serviços para o exterior e são alvo do processo de racionalização. $\mathrm{O}$ trabalho do teleatendente é pautado pelo uso da tecnologia da informação, que organiza e controla a atividade de trabalho. Estas características o associam a uma atividade econômica promissora, ao mesmo tempo que o trabalho é carregado de significados negativos, o que faz com que seja considerado um emprego passageiro, por ser penoso, já que o ritmo é intenso, com poucas pausas de descanso, e com regras e normas que padronizam e enrijecem a conduta dos operadores.

Observa-se que existem diferentes fontes de controle sobre seu trabalho e uma delas provém dos próprios operadores que vigiam uns aos outros. Os entrevistados revelam a importância de "não fazer corpo mole", de "ter que produzir", caso contrário, "você arrumará problemas com a sua equipe". As observações de pesquisa confirmam o que tem sido apontado pela literatura, sobre a existência de uma forma de controle mais difusa, distribuída, mas não por isso menos atuante.

O mal-estar provocado pelo controle social vai além da sensação de pressão por produção, porque dificulta a criação de vínculos de amizade, uma vez que estimula a competição entre os pares. Ao exercerem controle sobre os colegas, os operadores auxiliam a organização no processo de disciplina às normas e regras impostas. A competição e suas consequências são características da organização do trabalho em grupo também observadas em outras esferas produtivas. 
O controle, a cobrança e a pressão por produção, a competição que estimula as desavenças entre os operadores, a padronização que dificulta a autonomia de decisão acabaram por criar um estigma negativo da profissão, reforçado pela visão de que é um emprego passageiro, sem perspectiva de ascensão. Este estigma negativo faz com que os trabalhadores não se identifiquem com a profissão que exercem, o que se reforça no caso da central pesquisada, dado o significado negativo que a função de cobrador possui na sociedade. Este cenário dificulta a formação de laços de amizade e de identificação com os pares, o que reflete na baixa adesão sindical, agravada pela disputa entre os órgãos sindicais.

\section{Referências}

ANTONELLI, V. Mercado de soluções para call center no Brasil. Portal do Callcenter, 2008. Disponível em: $<\mathrm{http}$ ://portaldocallcenter.consumidormoderno.com. br/tecnologia/novidades/mercado-de-solucoes-paracall-centers-cresce-no-brasil?searchterm=cresciment o+para+2012>. Acesso em: 10 out. 2008.

ARAÚJO, Â. M. C. et al. Globalização, estratégias gerenciais e respostas operárias. CNPq, 2006. Relatório de pesquisa.

ARAGÃO, M. Lei impõe investimento em call center. Estado de São Paulo, São Paulo, 09 ago. 2008. Disponível em: <www.estadão.com.br>. Acesso em: 10 ago. 2008.

ASSOCIAÇÃO BRASILEIRA DE TELESSERVIÇOS - ABT. A prática de offshore no Brasil. ABT, 2006. Disponível em: <http://www.abt.org.br>. Acesso em: 22 abr. 2006.

BAGNARA, S.; MARTI, P. Human work in call centers: a challenge for cognitive ergonomics. Theoretical Issues in Ergonomics Science, v. 2, n. 3, p. 223-237, jul. 2001. http://dx.doi.org/10.1080/14639220110104943

BARNES, A. The construction of control: the physical environment and the development of resistance and accommodation within call centers. New Technology, Work and Employment, v. 22, n. 3, p. 246-259, nov. 2007. http://dx.doi.org/10.1111/j.1468-005X.2007.00197.x

BATT, R.; DOELLGAST, V. Groups, teams and the division of labor. Interdisciplinary perspective on the organization of work. In: ACKROYD, S. et al. The oxford handbook of work and organization. Oxford: University Press, 2005. p. 138-162.

BATT, R.; HOLMAN, D.; HOLTGREWE, U. The globalization of service work: comparative institutional perspectives on call centers. Industrial \& Labor Relations Review, v. 62, n. 4, p. 453-488, 2009.

BEAUD, S.; PIALOUX, M. Retour sur la condition ouvrière: enquête aux usines Peugeot de SochauxMontbéliard. Paris: Fayard, 1999.

BORGES, A.; ROSA, J. L. Call centers avançam e já empregam 250 mil. Valor Econômico, São Paulo, p. 3, 03 jan. 2007.

BRAGA, R. Uma sociologia da condição proletária contemporânea. Tempo Social. Revista de Sociologia da USP, v. 18, n. 1, p. 133-152, jun. 2006. http://dx.doi. org/10.1590/S0103-20702006000100008
BRAVERMAN, H. Labor and monopoly capital: the degradation of work in the twentieth century. Nova York: Monthly Review Press, 1974.

BURAWOY, M. A transformação dos regimes fabris no capitalismo avançado. Revista Brasileira de Ciências Sociais, ano 5, n. 13, p. 29-50, 1983.

CALLCENTER.INF. Telesserviços cresce $\mathbf{1 0 \%}$ em 2008. 2009a. Disponível em: <http://www.callcenter. inf.br/estatisticas/default.asp?pag=matintegra $\& \mathrm{~m}$ atID=34669>. Acesso em: 05 jan. 2010.

CALLCENTER.INF. México já é $2^{\circ}$ maior destino de offshore do mundo. 2009b. Disponível em: <http:// www.callcenter.inf.br/especial/default.asp?pag=ma tintegra\&matID=37147>. Acesso em: 12 fev. 2010 .

CALLCENTER.INF. Ranking - radiografia do mercado. 2010. Disponível em: <http://ranking.callcenter.inf.br/ resumo>. Acesso em: 6 dez. 2010.

CARDOSO, A. Los sindicatos: representación de intereses y acción política del capital y trabajo en Brasil. Veredas: Revista del Pensamiento Sociológico, v. 16, p. 63-83, 2008. Disponível em: <http://bidi.xoc.uam. mx/fasciculos_revista.php?id_revista $=12>$.

CASTRO, N.; GUIMARÃES, S. Além de Braverman, depois de Burawoy: Novas vertentes analíticas na Sociologia do Trabalho. São Paulo. Revista Brasileira de Ciências Sociais, v. 6, n. 17, out.1991.

CONVERGÊNCIA DIGITAL. Telesserviços: setor empregará 850 mil em 2009. 2009. Disponível em: <http://www.convergenciadigital.com.br>. Acesso em: 10 out. 2008.

CORROCHANO, M. C.; NASCIMENTO, É. Sindicato de trabalhadores em telemarketing de São Paulo. Instituto Pólis e Ibase, set. 2007. Disponível em: <www. polis.org.br>.

DELBRIDGE, R. Life on the line in contemporary manufacturing. Oxford: Oxford University Press, 1998. http://dx.doi.org/10.1093/acprof :oso/9780198292333.001.0001

DEPARTAMENTO INTERSINDICAL DE ESTATÍSTICA E ESTUDOS SOCIOECONÔMICOS - DIEESE. Anuário dos trabalhadores: 2008. DIEESE, 2009. Disponível em: <http://www.dieese.org.br/anu/ anuarioTrabalhadores2008/index.htm>. Acesso em: 22 jan. 2010.

DRUCK, M. G.; FRANCO, T. A Precarização do Trabalho no Brasil: um estudo da evolução da terceirização no Brasil e na indústria da Bahia na última década. Revista Latinoamericana de Estudios del Trabajo, v. 13, p. 97-120, 2008.

DURAND, J.-P. La chaîne invisible: travailler aujourd'hui, flux tendu et servitude volontaire. Paris: Le Seuil, 2004. n. 39, p. 107-122.

EDWARDS, R. C. Contested terrain: The Transformation of the workplace in the twentieth century. Nova York: Basic Books, 1979.

FEDERAÇÃO DOS EMPREGADOS DE AGENTES AUTÔNOMOS DO COMÉRCIO DO ESTADO DE SÃO PAULO - FEAAC. Categorias Representadas. 2010a Disponível em: <www.feaac.org.br>.

FEDERAÇÃO DOS EMPREGADOS DE AGENTES AUTÔNOMOS DO COMÉRCIO DO ESTADO DE 
SÃO PAULO - FEAAC. Sindicatos. 2010b. Disponível em: <www.feaac.org.br>.

FIGUEIREDO, M. G. et al. Reestruturação produtiva, terceirização e relações de trabalho na indústria petrolífera offshore da Bacia de Campos (RJ). Gestão \& Produção, v. 14, n. 1, p. 55-68, 2007.

FOUCAULT, M. História da sexualidade I: a vontade de saber. 14. ed. Rio de Janeiro: Graal, 2001.

FOUCAULT, M. Vigiar e punir: nascimento da prisão. Tradução de Raquel Ramalhete. Petrópolis: Vozes, 1987.

GEORGES, I. P. H. Flexibilização do mercado de trabalho e novas formas de mobilidade: carreiras femininas no setor terciário. Revista Latinoamericana de Estúdios del Trabajo, año 11, n. 18, p. 121-145, 2006.

GEORGES, I. P. H. Trajetórias profissionais e saberes escolares: o caso do telemarketing no Brasil. Formations professionnelles au Nord et au Sud: politiques et pratiques, set. 2005. p. 139-162. Adaptação do artigo original, publicado na França: "Trajectoires professionnelles et savoirs scolaires - le cas du télé-marketing au Brésil", Les Cahiers de la recherche sur l'éducation et 146 les savoirs, n. 4.

GITAHY, L. Inovação tecnológica, subcontratação e mercado de trabalho. São Paulo em Perspectiva, v. 8, n. 1, p. 144-153, jan./mar. 1994.

GUIA CALL CENTER BRASIL. Informações sobre call center. 2010. Disponível em: <http://www.guiacallcenter. com/>. Acesso em: 30 jan. 2010.

HELOANI, J. R.; CAPITÃO, C. G. A saúde mental e psicologia do trabalho. São Paulo em Perspectiva, v. 17, n. 2, pp. 102-108. 2003. http://dx.doi.org/10.1590/ S0102-88392003000200011

INSTITUTO BRASILEIRO DE GEOGRAFIA E ESTATÍSTICA - IBGE. Estrutura produtiva empresarial brasileira 1994: Resultados do Censo Cadastro 1995. Rio de Janeiro: IBGE, 1997.

INSTITUTO BRASILEIRO DE GEOGRAFIA E ESTATÍSTICA - IBGE. Cadastro central de empresas 2000. Rio de Janeiro: IBGE, 2002. Disponível em: <http://ibge.org.br>.

INSTITUTO BRASILEIRO DE GEOGRAFIA E ESTATÍSTICA - IBGE. Cadastro central de empresas 2004. Rio de Janeiro: IBGE, 2007a. Disponível em: <http://ibge.org.br>.

INSTITUTO BRASILEIRO DE GEOGRAFIA E ESTATÍsticA - IBGE. Sistema de Contas Nacionais - Brasil 2000-2005 - IBGE divulga nova série do Sistema de Contas Nacionais. Rio de Janeiro: IBGE, 2007b. Disponível em: <http://ibge.org.br>.

INSTITUTO BRASILEIRO DE GEOGRAFIA E ESTATÍSTICA - IBGE. Em 2008, PIB cresceu 5,1\% e chegou a R\$ 2,9 trilhões. Rio de Janeiro: IBGE, 2009. Disponível em: <http://ibge.org.br>.

JAMIL, G. L.; SILVA, F. B. Call Center e Telemarketing. Rio de Janeiro: Axcel Books do Brasil Editora, 2005.

KON, A. Características econômicas das indústrias de serviços no Brasil: uma comparação entre empresas de capital estrangeiro e de capital nacional. In: DE NEGRI, J. A.; KUBOTA, L. C. (Org.). Estrutura e dinâmica da produtividade do setor de serviços no Brasil. Brasília: IPEA, 2006. p. 133-192.
KUBOTA, L. C. A inovação tecnológica das firmas de serviços no Brasil. In: DE NEGRI, J. A.; KUBOTA, L. C. (Orgs.). Estrutura e dinâmica da produtividade do setor de serviços no Brasil. Brasília: IPEA, 2006. p. 35-72.

LARANJEIRA, S. M. G. A reestruturação das telecomunicações e os sindicatos. Revista Brasileira de Ciências Sociais, v. 18, n. 52, p. 82-106, jun. 2003

MOCELIN, D. G.; SILVA, L. F. C. O Telemarketing e o perfil sócio-ocupacional dos empregados em call centers. Caderno CRH, v. 21, n. 53, p. 365-387, maio/ago. 2008.

NORONHA, E. G. Ciclo de greves, transição política e estabilização: Brasil, 1978-2007. Lua Nova, v. 76, p. 119-168, 2009.

OLIVEIRA, E. L. Terciarização do Mercado de Trabalho Brasileiro. In: ENCONTRO NACIONAL DE ESTUDOS DO TRABALHO, 12., 2001, Salvador. Anais... Salvador, 2001. v. 1.

OLIVEIRA, S. M. Reestruturação das telecomunicações no Brasil: uma re(visão) das estratégias de gestão de produção e das relações de trabalho na cadeia produtiva: Estudo de caso da telefonia fixa em São Paulo - 1999 a 2003. 2005. Tese (Doutorado em Sociologia)-Universidade de São Paulo, São Paulo, 2004.

OLIVEIRA, M. M. et al. Relatório da Indústria de Call Center no Brasil 2005. São Paulo: Pontifícia Universidade Católica de São Paulo, Programa de Pós-Graduação em Administração, 2005. The Global Call Center Industry Project.

ROSENFIELD, C. L. Paradoxos do capitalismo e trabalho em call centers: Brasil, Portugal e Cabo Verde. Caderno de Recursos Humanos, v. 20, n. 51, dez. 2007.

SALERNO, M. S. Da rotinização à flexibilização: ensaio sobre o pensamento crítico brasileiro de organização do trabalho. Gestão \& Produção, v. 11, n. 1, p. 21-32, jan./abr. 2004. http://dx.doi.org/10.1590/ S0104-530X2004000100003

SALERNO, M. S. Projeto de organizações integradas e flexíveis: processos, grupos e gestão democrática via espaços de comunicação-negociação. São Paulo: Atlas, 1999.

SANCHES, A. T. Terceirização e Terceirizados no setor bancário: Relações de emprego, condições de trabalho e ação sindical. 2006. Dissertação (Mestrado)-Pontifícia Universidade Católica de São Paulo, São Paulo, 2006.

SEGNINI, L. R. P. Relações de gênero e racionalização do trabalho em serviços. In: SEMINÁRIO TRABALHO E PRODUTIVIDADE NO TERCIÁRIO, 1999, São Paulo. Anais... São Paulo: 1999.

SILVA, R. Perfil e reordenamento das atividades terciárias na década de 90 no Brasil: $\mathrm{O}$ trabalho no setor terciário. Emprego e desenvolvimento tecnológico. São Paulo: DIEESE; Campinas: Cesit, 2005.

SILVA, A. M., DE NEGRI, J. A.; KUBOTA, L. C. Estrutura e dinâmica do setor de serviços no Brasil. In: DE NEGRI, J. A.; KUBOTA, L. C. (Org.). Estrutura e dinâmica da produtividade do setor de serviços no Brasil. Brasília: IPEA, 2006. cap. 1.

SILVEIRA, S. M. Organizações e usos das bases de informação para o atendimento a clientes em call centers. 2006. Dissertação (Mestrado em Ciência da 
Informação)-Escola de Ciência da Informação, Universidade Federal de Minas Gerais, Belo Horizonte, 2006.

SINDICATO DOS EMPREGADOS DE AGENTES AUTÔNOMOS DO COMÉRCIO E EM EMPRESAS DE ASSESSORAMENTO, PERÍCIAS, INFORMAÇÕES E PESQUISAS E DE EMPRESAS DE SERVIÇOS CONTÁBEIS DE CAMPINAS E REGIÃO - SEAAC Campinas. Categorias. 2010. Disponível em <www. seaaccampinas.org.br/site/categorias.asp $>$.

SMITH, V. New forms of work organization. Annual Review of Sociology, v. 23, p. 315-339, 1997. http:// dx.doi.org/10.1146/annurev.soc.23.1.315

SEWELL, G. The discipline of teams: the control of team-based industrial work through electronic and per surveillance. Administrative Science Quaterly, v. 43, n. 2, p. 397-416, 1998. http://dx.doi.org/10.2307/2393857
VENCO, S B. Centrais de teleatividades: o surgimento dos colarinhos furta-cores? In: ANTUNES, R.; BRAGA, R. (Org.). Infoproletários: degradação real do trabalho virtual. São Paulo: Boitempo, 2009. p. 153-171.

VENCO, S B. Centrais de atendimento: a fábrica do século XIX nos serviços do século XXI1. Revista Brasileira de Saúde Ocupacional, v. 31, n. 114, p. 7-18, jul./dez. 2006. http://dx.doi.org/10.1590/S0303-76572006000200002

VENCO, S B. Telemarketing, o emprego que desemprega. 1999. Dissertação (Mestrado em Educação)Faculdade de Educação, Universidade Estadual de Campinas, Campinas, 1999.

ZARIFIAN, P. Das Mutações do Trabalho à Competência. In: ZARIFIAN, P. Objetivo Competência: Por uma Nova Lógica. São Paulo: Atlas, 2001. p. 37-65. 